\title{
The design of interactive installation for environmental education on climate change in Antarctic based on open-source programming language
}

\author{
Li Huiqing $^{1^{*}}$ \\ ${ }^{1}$ Department of Product Design, School of Architecture and Art, Central South University, Changsha, Hunan, China
}

\begin{abstract}
With the advancement of modern technology and the growing development of new media technology, the computer technology programming language has been increasingly applied to the world of art. Meanwhile, the scientific technology, design art and the growing aesthetic standard have promoted the development of the art of new media interactive installation. With the accelerated global warming and sea level rise, the coastal areas are confronting a great risk. On a case study of the "The vanishing Antarctic continent", the paper discussed the creation of interactive installation art design with social significance through the computer programming language, calling for the environmental protection while stimulating the human-computer interaction and resonance.
\end{abstract}

\section{The overview of development platform for Processing and Arduino}

\subsection{Processing}

Processing is a programming language that specializes in visualizing the input signal based on Java. Its superiority is that it is a kind of source code that is not only free for uses to access, but also allow them to modify and learn the source code of Processing, as a result, it can suffice the diverse demands of users. The users can utilize the graphical interfaces flexibly and render the graphic through computer hardware. Processing can make the interaction of all kinds of computer hardware and induction system achievable due to its accessibility, therefore, it is extremely suitable for the nonprofessional programmers to learn and use [1]. The greatest strength of Processing is profession, applicability and efficiency. It is a programming language focusing on the electronic art and visual interaction, providing new visualization technology support for designers and artists, that is why it is professional. Although it is the extension of Java language, it has simpler grammars and rules than Java and also adds the performance of interface and interaction, making it accessible and applicable. Compared with other advanced language, Processing is not only applicable for people who intend to process the animation and sound through programming edit, but also for undergraduates, freelance artists, professional designers and those who are interested in to learn, develop prototype and fabricate [2].

\subsection{Arduino}

Arduino is a simple $\mathrm{I} / \mathrm{O}$ platform that can independently communicate with interactive software, such as Processing, flash and Max/MSP [3]. Arduino platform mainly consists of Arduino development board, Arduino core library and Arduino IDE [4]. Among which, Arduino IDE is a software platform to write a run program, which can be transferred to the Arduino development board after writing the Sketch file [5]. On the Arduino development board, there are many interfaces, including digital and analog input and output, power, communication and micro-processing controller. Through the interfaces, Arduino mainboard can connect with various sensors to access information data, which will be transferred to Arduino main board by input interface. Then, the received form will be compiled by the Arduino mainboard, at last, the corresponding commands will be transmitted by the microphone, LED and other output installations of output interface, executing the whole set of design system [6]. The interaction of Arduino and participants are mainly achieved through sensor hardware, such as temperature sensor. The electronic controller of Arduino will receive the command of sensor and send the edited program to the corresponding sensor hardware, controlling the effect of lighting and sound [7].

\section{The overview of art of interactive installation}

The art of interactive installation is an artistic form. It takes the computer hardware and software as carrier and

\footnotetext{
* Li Huiqing: lihuiqing@csu.edu.cn
} 
processes them in an artistic manner so as to achieve the interaction of human and computer or different people [8]. The advanced technology generates and develops the art of interactive installation. It is a conversion of artistic form under the conventional mode. Through the technical media, the traditional "display design" focusing on object has now transformed to the "experience design" that emphasizes on people. The audience can obtain information and attention through the interaction with the installation and firsthand experience, breaking through the "static aesthetic" of conventional art works. It can make people visually experience the art while interacting with the works and change the form and state partially. In this way, participants can actually feel, which is quite different from the traditional art works [9].

The art of interactive installation has three major features, the participated interactive experience, the scientific information transmission, and the time-validity. The interactive installation art work requires that the participants energetically enjoy and experience. It integrated various scientific elements, knowledge of multiple disciplines and the feature of the era. As for the time-validity, compared with traditional art work, the art of interactive installation generally is not of high collection value, as a matter of matter, the intention of such work is not for collection. It merely aims to attract participants through diverse interactive forms, enhancing the experience and viewing value [10].

\section{The integration of Processing, Arduino and the art of interactive installation}

Before the "digital media" and "digital technology" are well developed, the designers conveyed their design concept in a one-way manner through the installation work, and the audiences acquired information also in a one-way and passive manner. Interactive elements were barely seen from the communication process of audiences and design work. With the advent of graphic design language, such as Processing, the communication form between audiences and the artistic design work has changed tremendously [11]. Processing is software platform that focuses on the visualization of signals. The reason why Processing can create multi-form interactive art work is that it can integrate the devices, such as Arduino and sensor. In this way, the communication between audiences and art can be truly achieved [3]. The programming language of Arduino is designed based on the graphic design language, such as Processing. With such design language, the electric signals input by Arduino can be transmitted to graphics and animations with various change [5]. The interactive communication of Processing and Arduino makes the communication between audiences and designs more extensive. The audiences start to interpret the design work with their own insight and idea, enhancing the interactive participation. Meanwhile, the designers can capture the useful feedback during the experience process of audiences so as to improve their future designs, promoting the two-way communication among designers, design works and the audiences [2].

With the popularization of informatization and the development of interdisciplinary integration, the boundary between art and technology has gradually been vague. The combination of computer technology and art becomes closer.

\section{Design practice - "The vanishing Antarctic continent"}

\subsection{The background of the creativity}

In the fifth climate change evaluation report, the IPCC pointed out that the global sea level has been risen increasingly since the 19th century [12]. With the deterioration of global warming, the increasing rise of global average sea level exacerbates. Melting of land glaciers and the expansion of upper layer of seawater due to warming are mainly the reasons for such situation. In particular, the melting of land glaciers has more significant impact on the sea level rise [13]. Antarctic glacier, the largest one on the earth, will be the main force of global sea level rise and outrun Greenland island for its melting amount, if the glacier melting accelerates at an increasing tendency [14]. The majority of the islands and coastal areas in the world will be in a risk of being inundated within the 21th century if proper measures were not taken [13].

\subsection{The concept of the creativity}

Global warming has made the average temperature rise in the world, especially the polar regions. With the accelerated melting of glaciers and glacial sheet, the sea level rises rapidly. The lower elevation areas, such as ocean zone and coastal areas, will be inundated by ocean. The installation of "The Vanishing Antarctic continent" represents the glaciers and glacial sheet in Antarctic, the tactile temperature of people signifies the global air temperature and the graphic interfaces have been utilized to display the sea level of the world. When it contacts the body temperature, the interface will change accordingly so as to simulate the process of sea level rise in a simply way. The installation combines the computer programming language technology and artistic expression. Through the stimulation of touch and vision, people can experience the process of sea level rise, enhancing the sense of crisis of global warming.

\subsection{Preparation and user experience}

\subsubsection{Preparation}

In terms of appearance, the installation consists of three modules, which are "Antarctic", "Ocean" and "World topography". The first module, namely, "Antarctic" is comprised by six pieces of acrylic boards in milky white; the second module, "Ocean" mainly consists of four deep-sea stickers, one seabed sticker and a sticker of the 
outline of the Antarctic continent; as for "World topography", it is mainly displayed by the screen. In terms of the circuit, it consists of the temperature sensor symbolizing the climate, mp3 module that represents the seawater rise and the display screen that shows the change of the sea level in the world.
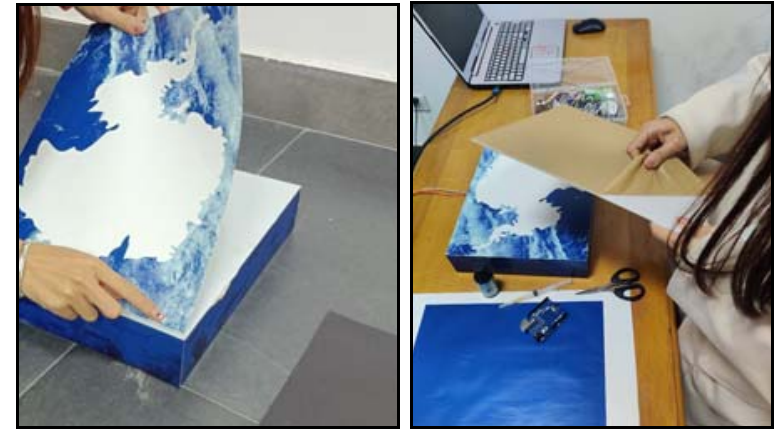

Fig. 1. Initial preparation work.

\subsubsection{Process of user experience}

When people place their hands on the installation box of the "The Vanishing Antarctic continent", the palm temperature represents the average temperature of the earth. The longer the time, the darker the light of "The Vanishing Antarctic continent" and the more intense the sound of the seawater, meaning that the sea level is rising. The blue, representing the ocean, is expanding. The coastal areas are inundated. At last, the original land will be covered with seawater. When people release their hands, the installation will turn bright and the world sea level on the interface will resume. In this way, people are called for their attention on the severe consequences of the sea level rise due to the global warming caused by the glacier melting.
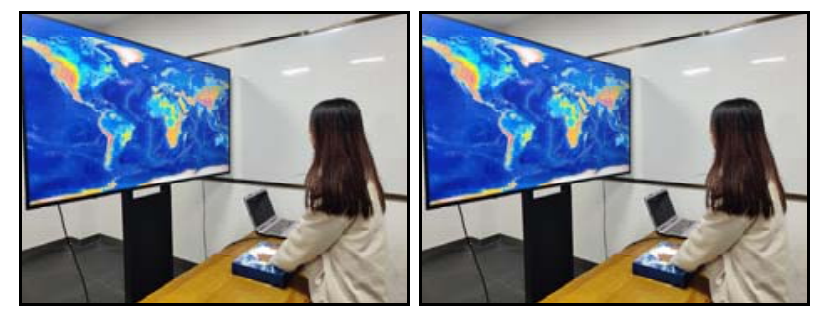

Fig. 2. User experience process.
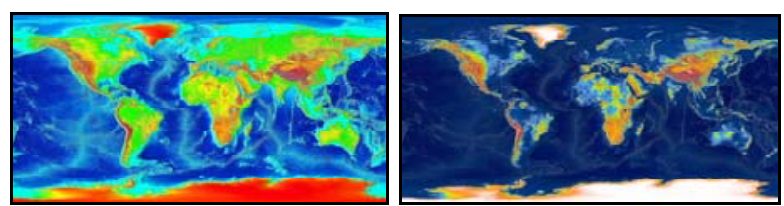

Fig. 3. Part of the change process diagram of the interface.

\subsection{Implementation of critical technologies}

\subsubsection{The combination of Arduino, LED and temperature sensor.}

The installation mainly utilizes the resistance type temperature sensor. The luminance of LED will be regulated, as the higher the temperature of negative temperature coefficient thermistor, the smaller the resistance value. When participants put their hands on the "The Vanishing Antarctic continent", the temperature will rise, the resistance will drop, and LED will be brighter. When the resistivity $t$ is lower than 512, LED turns dusk, symbolizing that the glaciers in Antarctic is melting. The installation sets up a 1-second delay (1000) to make the gradual change more distinct. On the contrary, when the resistivity is rising, which is, the temperature sensed is lower, LED will be brighter, representing that "The Vanishing Antarctic continent" reemerges.

\subsubsection{The combination of Arduino, mp3 module and temperature sensor.}

Connect the mp3 module to the programming hardware and set the sound as the output mode. The sound volume of mp3 module will be contrary to the brightness of LED through the Arduino programming platform. The brighter the LED, the smaller the sound of seawater, vice versa. The darker the LED, the fast the melting of the glaciers. The seawater is rising and the surging seawater flaps the glaciers that are going to melt away.

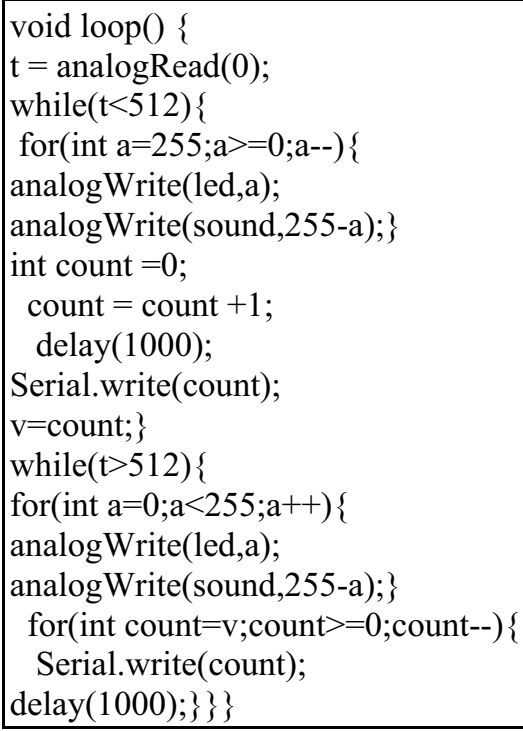

Fig. 4. The run program of gradual change of the sound and the brightness.

\subsubsection{The combination of Arduino and Processing.}

Arduino mainly controls the electronic interaction of computer hardware and induction system, while, Processing is responsible for the visual interaction. The brightness of LED and the volume of sound will be regulated by Arduino, meanwhile, the corresponding change will be transmitted to the Processing to correspond to the images. The images will change along with the time set by the Processing. The ocean gradually inundates the land. The available areas for human are less, until vanishes. At last, all continents will sink into 
the sea and the earth becomes a "blue planet" that surrounded by the ocean.

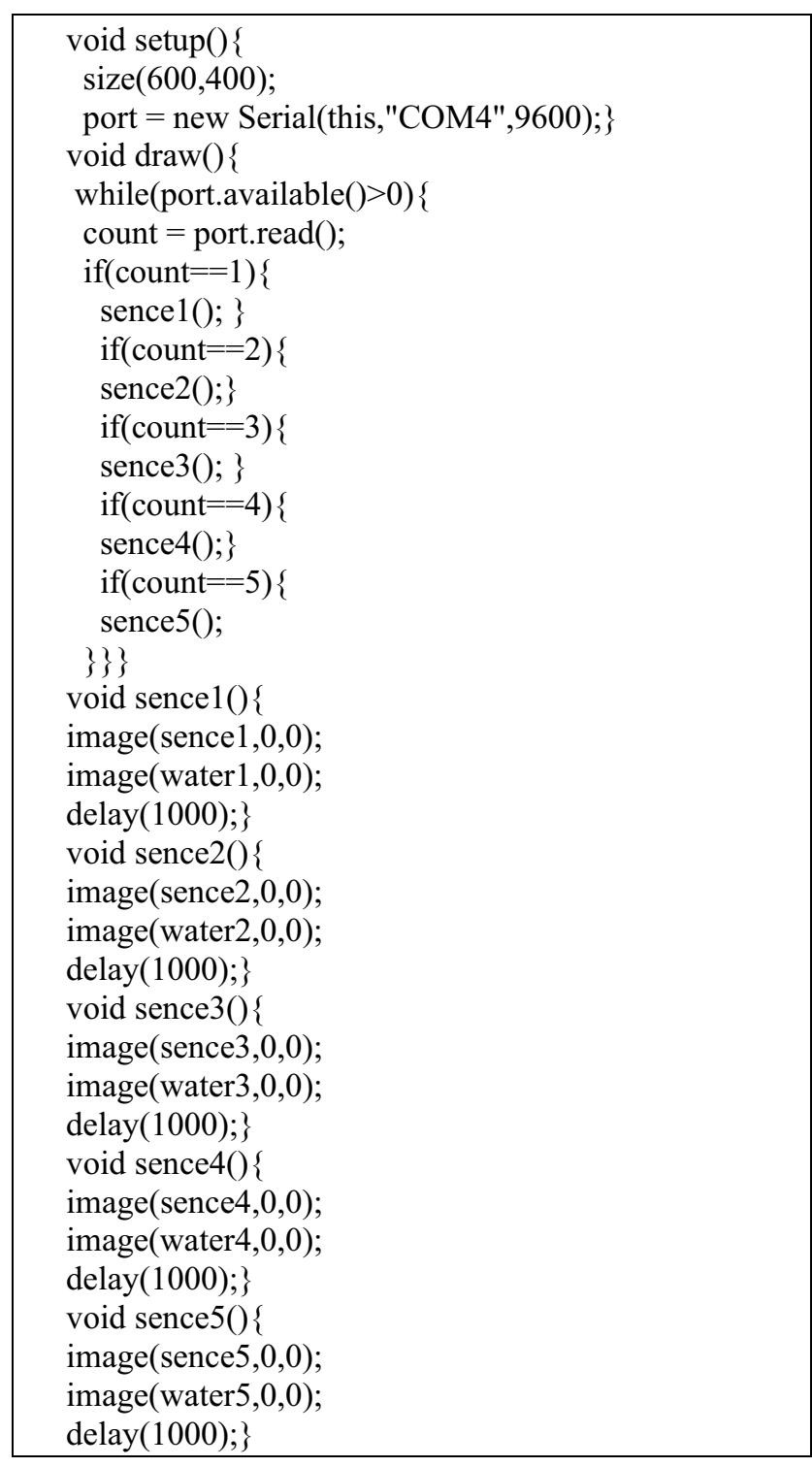

Fig. 5. The program of gradually changing sea level.

\section{Conclusion}

The work has profound significance of popular science publicity and education as it has a strong sense of interest, science and participation. The body temperature has been utilized to obtain the temperature data so as to simulate the change of global temperature. The intelligent hardware installation emulates the Antarctic glaciers so as to simulate the global warming and sea level rise through the human-computer interaction, promoting the environmental awareness of the mass to a certain extent. Different from the propaganda form of improving global warming through energy conservation and emission reduction, "The Vanishing Antarctic continent" allows people to experience the entire process of change with the Processing and Arduino programming and hardware, making the interaction between the work and audiences stronger. It does not only the partial principle about why the sea level rises but also warn its hazardous nature, therefore, it has profound educational significance and strengthens the environmental awareness of the participants.

The integration of art design and scientific technology is irresistible. The designers shall focus more on the learning and practice of inter-discipline and the diverse presentation forms during the creation. For instance, Processing and Arduino programming and hardware can make the perfect integration of art and technology feasible. The charisma of art creation can be revealed by making use of the electronic interactive design so as to display the potential of human-machine interaction to the largest extent. It can promote the development of artistic design style, expand the depth and extent of the designer's thinking, thus creating more design works with the integration of art and science and elaborating the aesthetics of the era in a multidimensional manner [7].

\section{References}

1. $\mathrm{Xu}$ Yang. (2018). Application Research of Processing in Digital Media Art Major Teaching. Research in Fine Arts Education (07),102-103.

2. Ge Wen.(2020). Application Analysis of Interactive Graphic Programming Language Processing. Industrial Science and Technology Innovation (24),35-36.

3. Wang Xin.(2019). Application Research of Computer Generative Art Based on Processing. Art and Design (Theory)(Z1),64-65.

4. Cai, R. Y. (2012). The principle and application of Arduino. Electronic Design Engineering, 16,155157

5. Miao Lulu. (2013). Research on the development of interactive product prototypes based on the Arduino platform (Master's thesis, Shanghai Jiaotong University).

6. Ai Qing. (2018). The application and practice of Arduino open source hardware in the art product design profession. Fashion of Tomorrow (01), 62.

7. Fang Jiao. (2020). On the application and development of Arduino open source hardware in fashion art. Western Leather (17), 120-121.

8. Dong Feiran. (2013). Design and realization of installation art based on interactive multimedia technology (Master's thesis, Shanghai Jiaotong University).

9. Meng Yang. (2020). Research on Interactive Design Based on New Media Interactive Installation Art. Chinese Artist (04), 89+195.

10. Liu Xin. (2020). Analysis of the sensory experience effects of interactive installation art in the digital environment. Art Book (03), 228-229+306.

11. Chen Xiaowei \& Li Jinlei. (2020). Programming art creation under digital media interaction-Taking Processing as an example. Art Education (03), 130133. 
12. Working Group I of IPCC. Climate change 2013: the physical science basis [R]. New York: Cambridge University Press, (2013)

13. Cai Rongshuo \& Tan Hongjian. (2020). The impact and risks of accelerating sea level rise on lowaltitude islands, coastal areas and society. Progress in climate change research (02), 163-171.

14. Zhang Jun. (2013). The melting of Antarctic glaciers is intensifying. Geography Education (Z2), 124. 